\title{
Could Some Nonhemostatic Plasma Proteins Serve as Refuse Collectors for Fibrin(ogen)?
}

\author{
Rustem I. Litvinov ${ }^{1}$ John W. Weisel ${ }^{1}$ \\ ${ }^{1}$ Department of Cell and Developmental Biology, Perelman School of \\ Medicine, University of Pennsylvania, Philadelphia, Pennsylvania, \\ United States
}

Thromb Haemost 2019;119:1900.
Address for correspondence Rustem I. Litvinov, MD, PhD, Department of Cell and Developmental Biology, Perelman School of Medicine, University of Pennsylvania, Philadelphia, PA 19104, United States (e-mail: litvinov@pennmedicine.upenn.edu).
In the October issue of Thrombosis and Haemostasis, Talens et $\mathrm{al}^{1}$ proposed a general physiological role for certain plasma proteins previously shown to bind strongly but noncovalently to fibrinogen and/or fibrin. After excluding the proteins with known hemostatic activities, the authors recognized that some of the remaining fibrin-bound proteins (clusterin, haptoglobin, $\alpha 2$-macroglobulin, apolipoproteins $\mathrm{E}$ and $\mathrm{AI}$, albumin, serum amyloid $\mathrm{P}$, and $\alpha 1$-antitrypsin) belong to a family of "extracellular chaperones."2 Chaperones assist in refolding misfolded proteins in the endoplasmic reticulum, keeping them soluble by inhibiting aggregation, and facilitating intracellular protein trafficking. This concept has been extended to extracellular fluids, including blood, for several proteins that share functional properties with intracellular chaperones.

The authors hypothesized that fibrin formation is analogous to protein deposition diseases known to result from aggregation of misfolded proteins and that the extracellular chaperones can prevent fibrin formation and/or eliminate aged fibrinogen and fibrin once it has done its job. To prove this hypothesis, the authors established a parallelism between binding of the nonhemostatic plasma proteins to fibrin and the content of cross- $\beta$-structures in fibrinogen and fibrin, a signature of protein misfolding or unfolding. The cross- $\beta$-structures in fibrinogen and fibrin were formed by prolonged heating of plasma (mimicking unfolding that occurs with aging) as well as upon enzymatic conversion of fibrinogen to fibrin, in which formation of $\beta$-structures can occur. ${ }^{1,3}$ Also, the authors showed an inhibitory effect of caseins (known as milk chaperones) on fibrin formation.

It seems plausible that binding of certain plasma proteins targets both old fibrinogen and fibrin for clearance from the intravascular space and facilitates their proteolytic degradation, although the evidence so far is indirect. Whether or not the specific interactions of nonhemostatic plasma proteins can modulate fibrin(ogen) turnover is an intriguing idea that requires further investigation.

Conflict of Interest

None declared.

\section{References}

1 Talens S, Leebeek FWG, Veerhuis R, Rijken DC. Decoration of fibrin with extracellular chaperones. Thromb Haemost 2019;119(10): 1624-1631

2 Wyatt AR, Yerbury JJ, Ecroyd H, Wilson MR. Extracellular chaperones and proteostasis. Annu Rev Biochem 2013;82:295-322

3 Marx J, Hudry-Clergeon G, Capet-Antonini F, Bernard L. Laser Raman spectroscopy study of bovine fibrinogen and fibrin. Biochim Biophys Acta 1979;578:107-115 received

August 28, 2019

accepted

August 28, 2019 (c) 2019 Georg Thieme Verlag KG Stuttgart · New York
DOI https://doi.org/

10.1055/s-0039-1697619. ISSN 0340-6245. 